\title{
ENTRE EL MITO Y LA REALIDAD. LA SITUACIÓN DE LA MISTERIOSA ISLA ELIZABETH DE FRANCIS DRAKE
}

MATEO MARTINIC B. ${ }^{a}$

\section{RESUMEN}

En 1578, luego de una tranquila navegación por el estrecho de Magallanes, el marino inglés Francis Drake debió enfrentar las furias del océano Pacífico sur a lo largo de casi dos meses. En una de sus forzadas derivaciones la inacabable tormenta que castigó a su nave lo llevó muy adentro en el proceloso mar austral, circunstancia en la que él y sus compañeros encontraron una isla que llamaron Elizabeth fijando su posición aproximada. Esa isla nunca volvería a ser avistada por navegante alguno hasta el presente. La posteridad ha aceptado dicha observación y ha buscado una explicación para su desaparición atribuyéndola a la dinámica de la corteza terrestre, causa a su vez de variaciones en los fondos oceánicos. A propósito de la misma se informa acerca del progresivo conocimiento del relieve submarino en la zona del mar de Drake situada al sur de las islas Diego Ramírez, donde se ha encontrado recientemente el monte submarino Sars, una elevación abisal tan interesante como sugerente para ulteriores estudios científicos variados referidos a la interconexión biótica Antártica-Sudamérica en remotas épocas geológicas.

PALABRAS CLAVE: océano Pacífico sur, mar de Drake, isla Elizabeth, monte submarino Sars, dinámica abisal.

\section{BETWEEN MYTH AND REALITY. THE SITUATION OF THE MYSTERIOUS ELIZABETH ISLAND OF FRANCIS DRAKE}

\section{ABSTRACT}

In 1578, after a calm navigation through the Strait of Magellan, the English sailor Francis Drake had to face the furies of the South Pacific Ocean for almost two months. In one of his forced derivations the endless storm that punished his ship took him deep into the stormy southern sea, circumstance in which he and his companions found an island that they called Elizabeth fixing its approximate position. That island would never again be sighted by any sailor until now. Posterity has accepted this observation and has sought an explanation for its disappearance attributing it to the dynamics of the earth's crust, which in turn causes variations in the ocean floor. It is here reported the progressive knowledge of

Profesor Titular y Emérito, Universidad de Magallanes. Investigador Centro de Estudios del Hombre Austral, Instituto de la Patagonia, Universidad de Magallanes, Punta Arenas. $>$ mateo.martinic@umag.cl 
submarine relief in the Drake Sea area south of the Diego Ramírez Islands, where the Sars submarine mount has recently been found, an abyssal elevation as interesting as suggestive for further scientific studies referring to the interconnection of Antarctica and South America in remote geological times.

KEY WORDS: Southern Pacific Ocean, Drake Sea, Elizabeth Island, submarine mount Sars, abyssal dynamic.

\section{INTRODUCCIÓN}

El 6 de septiembre de 1578 el navegante Francis Drake, armado con patente de corso por su soberana la reina Isabel I de Inglaterra, salía del estrecho de Magallanes con su flotilla compuesta por tres naves, la Pelikan, capitana, la Elizabeth y la Marygold, para internarse en el océano Pacífico tras una travesía feliz de dieciséis días por el canal interoceánico, la más breve hasta entonces registrada en las casi seis décadas corridas desde su memorable descubrimiento. Pero no sería ese hecho el que le ganaría fama para la posteridad si no el más trascendente de ser el primero de su nacionalidad que penetraba en el gran océano occidental afectando seriamente la hegemonía que hasta entonces detentaba el Imperio Español en tan vasto espacio marítimo del planeta, como lo demostrarían a poco navegar sus audaces y afortunadas acciones corsarias.

Pero las condiciones climáticas que hasta entonces le habían favorecido como a ninguno de los navegantes precedentes que habían pasado por esa meridional zona del mundo se le tornaron tan adversas que su flotilla, antes de alejarse de ese ámbito, debió soportar por casi dos meses el castigo tormentoso del mar y del clima que significó la dispersión de las naves, con pérdida de una, la Marygold, la separación definitiva de otra, la Elizabeth, que tras muchos azares consiguió retornar a Inglaterra, y el voltejeo de la capitana por las aguas del Pacífico sur hasta una alta latitud, que tanto puso a prueba su solidez estructural $y$ sus condiciones marineras admirables ante tan bravísimo y prolongado zarandeo, como la competencia náutica del capitán Drake.

De esa memorable derivación, uno de los hechos más destacados del periplo mundial con el que concluiría el viaje, el corsario retornó amén de rico y famoso con la convicción de haber comprobado en el transcurso de aquel suceso el término meridional

1 Véase del autor el artículo 'Drake y el descubrimiento de la insularidad fueguina. La evidencia cartográfica', Anales del del continente americano y la existencia de un gran espacio oceánico al sur del mismo. Esta importante observación quedaría registrada tras su retorno mediante una producción cartográfica elaborada durante lo que restaría del siglo XVI y hasta principios del XVII que serviría de antecedente al ulterior hallazgo confirmatorio realizado por el holandés Willem Schouten en $1616^{1}$. Pero de esa memorable derivación quedaría para la posteridad una curiosa secuela que sin embargo del paso de los siglos no ha sido satisfactoriamente resuelta, como fuera el avistamiento de una misteriosa isla en el mar que llevaría su nombre y que no sería observada nuevamente por navegante alguno hasta el presente.

\section{LA FAMOSA DERIVACIÓN \\ AUSTRAL DE LA PELIKAN Y LA DISCUTIDA UBICACIÓN DE LA ISLA ELIZABETH}

El 9 de septiembre los barcos de Drake empujados por un fortísimo viento derivaron océano adentro hacia el suroeste hasta un punto cuyas coordenadas se estimaron ser $57^{\circ}$ de latitud sur y $82^{\circ}$ de longitud oeste aproximadamente, lugar en que desapareció la Marygold. Desde allí el voltejeo condujo a las otras dos naves con rumbo al noreste llegando a la vista del continente hacia los $51^{\circ}$ sur en un punto que más tarde se recordaría con el nombre de Bahía de la separación de los amigos, porque allí, en efecto, se apartaron entre sí las dos embarcaciones. La Elizabeth que se encontraba bajo el mando de John Winter consiguió dar con la boca occidental del estrecho de Magallanes e ingresó por él, según se ha visto, mientras que la capitana Pelikan a merced del mar embravecido derivó primero hacia el sur y sureste encontrando resguardo en proximidad de la isla Negra (Noir) hacia los 54 $15^{\circ}$ sur. Era entonces el 14 de octubre, lo que significa que para este buque el zarandeo

Instituto de la Patagonia, Serie Ciencias Humanas, 26, 5-22, Punta Arenas, 1998. 
duraba cinco semanas. La Pelikan zarpó desde allí en procura de un fondeadero más favorable en el litoral oceánico de la parte meridional del Estrecho, objetivo conseguido aproximadamente hacia los $53^{\circ}$ $20^{\prime}$ sur. En ese desconocido paraje la capitana se abasteció de agua y leña y sus tripulantes tuvieron trato con los nativos, tiempo durante el que se perdió una pinaza con siete hombres a bordo ${ }^{2}$. Solitaria, la nave comandada por Drake zarpó hacia el norte pero nuevamente fue empujada por los elementos desatados hacia el sudoeste muy lejos del continente. En ese trance se pudo avistar una isla solitaria en un punto que se situó hacia los $57^{\circ} 30^{\prime}$ de latitud sur y los $76^{\circ}$ de longitud oeste, esto es, a unas ochenta millas al suroeste del cabo de Hornos.

El día 24 de octubre el capitán Drake, asistido por su excelente piloto, el portugués Nuño da Silva, encontró un fondeadero "a tiro de cañón de tierra", con fondo de veinte brazas para su castigado barco. Permanecieron cuatro noches y tres dias en la ensenada de la isla; desembarcaron encontrando agua, leña y hierbas de gran virtud ${ }^{3}$. Estando allí observaron que la isla era pequeña, plana y con inclinación hacia el oriente, y que tenía un lago interior que se comunicaba por un canalizo con el mar, circunstancia bien recogida en un plano levantado por el capellán Francis Fletcher y que a algunos, siglos después, les recordaría a la volcánica isla antártica Decepción ${ }^{4}$. Bautizaron a esta solitaria Elizabeth, en homenaje a su soberana. El día 28 de octubre el viento soplaba del sur y Drake ordenó levar el ancla y navegación hacia el norte cosa de dos días arribando otra vez hasta la vecindad de la isla Negra; luego de una bienvenida parada zarparon de alli siempre con viento favorable siguiendo la costa, alejándose definitivamente de esa zona geográfica que les había sido tan adversa, navegación en cuyo transcurso Drake cambió el nombre Pelikan por el de Golden Hind a su buque, quizá en espera de que el mismo le fuera más propicio como en efecto lo fue ${ }^{5}$.

Retornaría a su patria Francis Drake el año

2 Esta gente protagonizó a partir de entonces una increíble aventura pues habiendo perdido de vista a la Pelikan se decidió navegar en busca del Estrecho y encontrándolo lo siguieron hacia el norte y el noreste hasta salir al Atlántico. Pasaron después incontables peripecias sobre las costas de Patagonia y otras de más al norte. De sus tripulantes sólo uno de ellos consiguió volver a Inglaterra ¡nueve años más tarde!

3 Felix Riesenberg, Cabo de Hornos (Librería Hachette S.A., Buenos Aires 1946), p. 66.
1579, como hemos escrito antes, al cabo de un exitoso y prolongado periplo habiendo completado la segunda circunnavegación del globo terráqueo, arribando a ella rico, afamado triunfante, para dar cuenta a su soberana de sus aventuras, tropelías e increíble botín obtenido, como de sus hallazgos geográficos. Aunque en un principio el manto del secreto pareció cubrir este último aspecto, poco a poco comenzaron a filtrarse algunas noticias sobre lo acontecido en la memorable travesía y, entre ellas, la referida al hallazgo de la isla Elizabeth. El primero en ocuparse de ello fue Richard Hakluyt, cronista de los hechos navales ingleses, quien recogió las informaciones y conoció a varios de los protagonistas del viaje. Pudo confirmar así la veracidad del avistamiento de la isla y aceptó como correctas las coordenadas geográficas estimadas por Nuño da Silva para su ubicación en el océano austral. No obstante esta conclusión en todas las cartas geográficas que pasaron a ser elaboradas y difundidas a contar de 1583 la isla mencionada fue situada en una posición marginal aunque adyacente al continente sudamericano.

Sin embargo, cosa curiosa, sin que nadie pusiera en duda el hallazgo en más de un siglo, entrada la centuria décimo octava la cartografía producida en Europa que así lo reconocía comenzó a figurarlo como una isla oceánica ubicada al sudoccidente y distante del continente identificándosela de distinta manera, bien como p.[port] decouvert par F. Drack (mapa de Guillaume de L'Isle, Paris 1703, mención repetida en todas las piezas del género del mismo autor de la primera mitad del siglo, referidas a Chile y la Tierra Magallánica); Terre de Drack (mapa de Nicolás de Fer, Paris 1720); p. F. Drak (mapa de Matthäus Seutter, Augsburg 1740); Port discove'd by Sr. Francis Drake (mapa de Emanuel Bowen, London 1740); Islas Elizabethides (mapa de Thomas Kitchin, London 1756); Port vue par Drack 1579 (mapa Hemisphere Meridional del conde de Redern, Paris 1762) e I. de Drack (mapa de Juan de la Cruz Cano y Olmedilla, Madrid 1775) ${ }^{6}$. Antes

4 Reproducido por Riesenberg en la página 90 de su obra.

5 Denominación tomada de la divisa de su patrono y valedor sir Christopher Hatton.

6 Según Riesenberg que hizo el registro en la década de 1930, la mención de que se trata con sus variaciones aparece en numerosos mapas del siglo XVIII, sin que tuviera éxito la averiguación acerca de la fecha (año) del registro más antiguo que, por ahora, situamos en 1703. 
todavía, en 1690, el marino español Francisco de Seixas y Lovera había elaborado un curioso mapa de la Región Magallánica con el objeto de apoyar la gestión que por la época realizaba ante el gobierno de España a fin de llamar su atención sobre el peligro que representaba para la jurisdicción hispana en el sur de América el interés que venía advirtiéndose por esa región por parte de Inglaterra ${ }^{7}$. Pues bien en esta pieza manuscrita, basada según su autor en los conocimientos adquiridos durante varios viajes por el meridión americano, se muestran en el ángulo inferior izquierdo del mapa, esto es, al suroeste de la Tierra del Fuego y en pleno océano Pacífico sus dos grandes islas y una menor que se identifican como Yslas de Seixas año 1678. Esta curiosa mención gráfica nos sugirió primeramente que la misma pudo basarse en alguna experiencia navegatoria durante la fecha indicada, pero ahora, en el contexto de la materia de que se trata, nos preguntamos si Seixas poseía alguna noticia sobre la derivación de Francis Drake ocurrida un siglo antes y, de esa manera, quiso hacer referencia a su hallazgo aunque atribuyéndoselo a sí mismo ${ }^{8}$.

No obstante lo reiterada que había sido durante el siglo XVIII, la producción cartográfica de la siguiente centuria hizo caso omiso de tal mención geográfica, razón por la que la misteriosa isla habría caído en el olvido. Pero promediando el siglo XIX y según la navegación velera aumentaba su movimiento por el paso austral de América no faltó quien en esos riesgosos periplos recordara la memorable derivación de Francis Drake y estuviera atento a cualquier señal en ese proceloso mar meridional que pudiera sugerir la desconocida ubicación de la que para entonces era ya la mítica isla Elizabeth. Tanto fue así que durante la navegación del velero norteamericano Pactolus en la madrugada del 6 de noviembre de 1885 , el viento amainó y se calmó el mar, y, advirtiendo una notable decoloración en las aguas, viraron hacia

7 Con ese propósito, en ese mismo año Seixas de Lovera publicó un libro que llamó Descripció Geographica y Derrotero de la Región Austral Magallánica, que fue presentado ante el Consejo de Indias y el monarca español (Véase al respecto nuestro artículo 'Rarezas cartográficas': I Las cuatro versiones del Mar de Chile del Padre Alonso de Ovalle. II El curioso Mapa de la Región Magallánica de Francisco de Seixas y Lovera (1690). Boletín de la Academia Chilena de la Historia, 107, 385-400.

8 Este mapa fue encontrado hace algunos años incluido en el ese lugar y sondearon tres veces, obteniendo en cada una de ellas de 67 a 70 brazas, arena negra y pequeñas rocas. Posición del sondeo, $56^{\circ} 30^{\prime}$ Latitud Sur, $74^{\circ} 20^{\prime}$ Longitud oeste. Luego navegaron treinta millas al sur antes de que el agua, siempre espesa y amarillenta, recobrara su color natural. La linea de demarcación era muy nítida ${ }^{9}$.

La difusión que pudo tener en los medios náuticos esta observación tal vez contribuyo a reactualizar en Gran Bretaña el nunca perdido interés en el asunto, como lo prueba la decisión del Discovery Committee, entidad que hacia 1930 se hallaba a cargo de los estudios e investigaciones que se referían a las reclamaciones del Reino Unido sobre la Antártica, para que el barco real de reconocimiento Discovery II realizara durante los años 1933 a 1935 una sucesión de recorridos exploratorios en la latitud $57^{\circ} 20^{\prime}$ sur, entre los $75^{\circ}$ y $80^{\circ}$ de longitud occidental, esto es, en el espacio en que los mapas antiguos ubicaban "el puerto de sir Francis Drake". Cada recorrido incluyó repetidos sondeos tanto sobre la situación históricamente conocida, como al norte y al sur de la supuesta ubicación de la isla.

Por otra parte, mientras tal había ocurrido y ocurría y aun desde mucho antes en el ambiente académico había surgido la preocupación por la materia en plan de precisar y aclarar lo acontecido durante la derivación austral de Drake, interés que se mantendría en forma casi intermitente hasta nuestra época. De esa preocupación han participado historiadores y marinos de gran prestigio, particularmente en el Reino Unido y en Estados Unidos, tales como James Burney, sir Julian Corbett, Henry R. Wagner, Zelia Nutall, Samuel E. Morison y Raymond Aker, entre otros. El punto central de la controversia que se generó en el transcurso del tiempo era el de la determinación de la más alta latitud que pudo alcanzar Drake en sus voltejeos en relación con la geografía ya perfectamente conocida y, precisar,

Atlas del cartógrafo portugués Joao Teixeira Ealbernaz y que se conserva en la Map Division de la Library of Congress, Washington D.C., Estados Unidos de América.

9 Informe de la Oficina Hidrográfica de San Francisco, firmado por el capitán hidrógrafo de la Armada de los Estados Unidos G. S. Bryan y fechado el 19 de agosto de 1891, citado por Riesenberg, op. cit., pp. 80 y 81. En el mismo documento se añade que un velero inglés que navegaba de San Francisco a Liverpool informa respecto a una decoloración de aguas en la misma posición, aproximadamente en la misma fecha. 
en consecuencia, cuál era el lugar que históricamente merecía el reconocimiento. La discusión académica, no obstante la diferencia en aspectos, ha convenido en que la posición geográfica alcanzada debiera situarse en el litoral sudoccidental fueguino en proximidad a la situación de la isla Hornos, relegando la ubicación oceánica originalmente aceptada a la condición de un simple mito ${ }^{10}$.

Ajeno a esa disputa, pero vivamente interesado en la solución de lo que con el correr del tiempo se había transformado en un misterio, Felix Riesenberg, capitán mercante norteamericano con probada veteranía en la navegación velera austral y escritor de temas marítimos, decidió abordar el asunto en el transcurso de los años de 1930.

Con un completo dominio de los antecedentes históricos, buena parte de ellos obtenidos por sus propias investigaciones, y de las materias náuticas involucradas, Riesenberg partió aceptando la veracidad de la observación de Francis Drake y compañeros en el Pacífico sur durante la derivación de la Pelikan en la tercera semana de 1578 , en procura de una explicación satisfactoria para toda la ausencia de avistamientos posteriores al de aquéllos sobre la misteriosa isla.

Su ponderado razonamiento y reflexiones a la vista de las diferentes informaciones que pudo reunir le llevó a concluir que su desaparición debía relacionarse con algún hecho natural acaecido en el curso del tiempo transcurrido desde el avistamiento hasta el momento de su propia preocupación. Fue precisamente el descubrimiento del banco Pactolus o Burnham ${ }^{11}$ el que le sugirió al prestigiado escritor y marino que un suceso telúrico desconocido, al parecer de carácter volcánico, podría haber sido la causa de la desaparición de la isla avistada por Drake y compañeros. En efecto, a la vista del elemental plano de Fletcher que muestra una isla de forma cuadrangular con un lago en el centro, coligió que la misma podría corresponder fisiográficamente al cráter de un volcán, en apariencia apagado, que en una hipotética reactivación habría originado una explosión superficial y la desaparición bajo el mar.

10 En esta controversia se han involucrado no sólo historiadores y escritores navales, sino entidades académicas prestigiadas tales como The National Maritime Historical Society of New York, The National Geographical Society, Dutch Cape Horners Foundation y The Royal Geographical Society de Londres, lo que da cuenta de la importancia atribuida al asunto.
Los recientes terremotos en Chile (enero de 1939), escribió a lo largo de la espina dorsal de la Cordillera andina, revelan lo que pudo haber fácilmente ocurrido en el extremo más meridional de aquella enorme cadena de cráteres. La isla de Elizabeth pudo haber sido reducida a la nada alrededor de un año después que Francis Drake dejó su puerto y recolectó sus "hierbas de gran virtud". Esta dentro de las probabilidades que tal haya sido su destino y su fin, al menos sobre la superficie del Mar del Sur ${ }^{12}$.

Los restos que habría dejado esa hipotética explosión volcánica habrían acabado removidos o desgastados por la acción de sucesivos embates de grandes bloques de hielo antártico (iceberg) desprendidos de la banquisa polar continental que flotan y se desplazan impulsados por la colosal fuerza de los vientos, opinión esta que Riesenberg fundó también en observaciones hechas por capitanes de veleros durante sus navegaciones por el mar de Drake, como le ocurriera a C.C. Dixon en 1860 a lo largo de un mes.

Abatida o desplazada, añadió Riesenberg, lo cierto es que la isla Elizabeth ha desaparecido, pero permanece su base, según lo revelan las pequeñas rocas y la arena negra extraídas por el escandalo del capitán Burnham.

Un examen de las profundidades demuestra que no existen suficientes aguas bajas como para haber sostenido a esta imponente isla de hielo durante cierto período de tiempo, salvo en lo que respecta al banco Burnham, directamente en la ruta de regreso de los veleros australianos.

Naturalmente, la superficie de la isla Elizabeth pudo haber sido destruida por una erupción. La solución del enigma atañe tanto al sismólogo como al geólogo, al historiador y al geógrafo. Pero, sobre todo, corresponde a la historia desentrañar la verdad del cúmulo de testimonios, la mayoría de ellos honestos, aunque mal interpretados por espacio de mucho tiempo ${ }^{13}$.

Las correspondientes descripciones, reflexiones y conjetura del antiguo marino fueron incluidas en

11

Denominación alternativa que dio a este accidente revelado en 1885 en homenaje al capitán James Burnham, capitán del Pactolus.

12 Op. cit., pp. 83 y 84.

13 Ibíd., p. 84. 
un capítulo especial ("La isla perdida de Sir Francis Drake"), parte de un libro referido a las navegaciones en la región meridional de América, en particular en torno al cabo de Hornos, que bajo este mismo título fue publicado originalmente en Londres en 1941 por Robert Hale Ltd., posteriormente traducido al español y reeditado por Librería Hachette S.A., Buenos Aires 1946. Obvio resulta agregar que por su calidad y amenidad esta obra es considerada desde hace tiempo como una de las clásicas de la literatura magallánica.

La difusión de este excelente libro en el mundo de habla hispana pudo influir quizá, una vez más, en la reactualización del asunto de la isla perdida de Drake. Tal lo demuestra el interés despertado sobre el tema en el ambiente público ilustrado en publicaciones chilenas de mediados del siglo $\mathrm{XX}^{14}$. Se sabe igualmente que en el transcurso de la primera expedición antártica nacional (1947) se habrían iniciado los registros del fondo marino en el área del banco Pactolus o Burnham, trabajo continuado después sistemáticamente durante varios años por la Armada de Chile en campañas hidrográficas especiales, que se extendió sobre todo al vasto sector triangular austral situado entre el cabo de Hornos y la península Antártica enmarcado por los meridianos $53^{\circ}$ y $76^{\circ}$ oeste (Véase la carta $N^{\circ} 12$ Sector Antártico Chileno, preparada y publicada por el Servicio Hidrográfico y Oceanográfico de la Armada de Chile, SHOA, entre 1947 y 1964). El objetivo del relevamiento, es claro, decía con el mejor conocimiento de la plataforma submarina, obteniéndose una información que permitiría constatar que el fondo marino más alto del talud de la plataforma continental parecía ser una suerte de llanura abisal con una profusión de elevaciones menores ${ }^{15}$. Pero ese vasto espacio reservaba una sorpresa.

\section{LA REACTUALIZACIÓN DE LA CUESTIÓN A LA LUZ DE UN SORPRENDENTE HALLAZGO GEOGRÁFICO RECIENTE (EL MONTE SUBMARINO SARS)}

Si el avistamiento de una isla océano Pacífico sur adentro correspondió a un hecho real, la pregunta

14 Mencionamos para el caso Tierra de Océano, de Benjamín Subercaseaux (Ediciones Ercilla, Santiago 1946) y El continente de los hombres solos, de Salvador Reyes (Ediciones Ercilla, Santiago 1956). Las referencias correspondientes al tema se encuentran en la página 195 , que se impone ante la ausencia de más observaciones durante el largo tiempo seguido hasta nuestros días es la de qué pudo suceder con esa misteriosa tierra. La explicación ofrecida por Riesenberg es valorable, pero a la luz del adelanto del conocimiento científico sobre la morfología y características del subsuelo registrado en el curso de un siglo hasta el presente cabe otra posibilidad: la del hundimiento de una tierra emergida como consecuencia de un fenómeno diferente.

El asunto nos lleva a una materia que atañe al mismo directamente como es la del conocimiento que actualmente se posee acerca de la dinámica histórica de la corteza terrestre, en especial de la parte de la misma que conforma el suelo submarino y su fisiografía.

Esa tierra desaparecida habría correspondido a la cima de un monte submarino, pero, a propósito ¿qué sabemos sobre la orografía de las planicies abisales y más específicamente sobre los montes submarinos?

Más que simples llanuras abisales como alguna vez pudo imaginarse en el pasado el suelo marino, la tecnología de medición de profundidades progresivamente mejorada y renovada ha hecho y hace cada vez mejor y más preciso el conocimiento sobre las partes de la corteza terrestre permanentemente sumergidas bajo los mares (batimetría). Ahora se posee una amplia noción sobre sus oroformas con sus sorprendentes extensas cadenas de montañas, sus no menos impresionantes fosas profundas y sus planicies desde las que se levantan aislados, agrupados o concatenados infinitos de montes submarinos.

Una apropiada imagen acerca del estado de ese conocimiento hacia el fin del siglo XX lo hemos encontrado en una carta que contiene el prestigiado Atlas of the World, elaborado y editado por The National Geographic Society (Revised Sixth Edition, Washington D.C. 1992). Se trata del mapa Earth's Crest (págs. 4-4), que da cuenta de los procesos y fenómenos que han moldeado la superficie submarina del planeta. Centrando la observación en el sector comprendido entre Sudamérica y la Antártica delimitado por los meridianos $60^{\circ}$ y $90^{\circ}$

texto y su sugerente nota al pie, y entre las páginas 60 y 62 , respectivamente.

15 Véase para el caso el mapa Earth's Crest incluido en el Atlas of the World, Revised Sixth Edition, The National Geographic Society, Washington D.C. 1992. 
oeste, es posible ver todo un complejo de oroformas definidas por los correspondientes taludes continentales y entre ambas imágenes que sugieren elevaciones notorias. Escribimos "sugieren" porque la escala del mapa no permite precisar tales formas (montes) y obliga al observador a imaginar sus posibles alturas y ubicaciones precisas. En su breve descripción complementaria, la especialista Carolyn H. Anderson advierte al lector sobre la dinámica de la corteza terrestre durante los últimos cuatro mil millones de años que ha dado como resultado que las posiciones y tamaños de las geoformas conocidas hayan cambiado (y cambien) permanentemente. Esa dinámica, por lo tanto, debiera incluir desplazamientos, ensanches, estrechamientos, hundimientos y elevamientos en diferentes combinaciones $y$ tiempos, $y$, por cierto, en un proceso que aunque aparentemente imperceptible es continuo.

El área que interesa, por otra parte, está definida por la Zona Económica Exclusiva (ZEE) ${ }^{16}$ del Mar Chileno que se extiende a partir de las aguas territoriales nacionales hasta unas 200 millas al sur y suroeste del cabo de Hornos, como referencia geográfica principal, y que contiene elevaciones -montes submarinos- que se nos ofrecen como puntos de particular interés en la materia que nos ocupa ${ }^{17}$.

Vivimos actualmente un período de la historia de la humanidad caracterizado, entre otros aspectos, por el sorprendente y acelerado adelanto de la tecnología de manera que, gracias al mismo, las investigaciones y estudios científicos han logrado y lograrán avances no menos sorprendentes y a veces hasta espectaculares. Este progreso tecnológico no ha excluido, como no excluye, ninguna actividad susceptible de utilidad para el avance del conocimiento y tal ha ocurrido con la batimetría de los fondos oceánicos con el fin de perfeccionarlo progresivamente y permitir disponer así, entre otros aspectos, de una mejor

16 Se define así al espacio oceánico que se extiende por 188 millas hacia el oeste, suroeste y sur de la línea que señala o acota el mar territorial de dominio soberano de la República de Chile en su parte continental americana y en torno a sus islas oceánicas.

17 De acuerdo con descripción contenida en la obra Geología Marina de Chile, se denominan así tres tipos de formas, una el Accidente submarino prominente aislado, cónico o a modo de pico, que se alza sobre una llanura abisal, noción sobre la corteza terrestre y su dinámica.

En este contexto comprensivo desde hace algunos años se han venido desarrollando investigaciones por cuenta del prestigioso British Antarctic Survey que han comprendido preferentemente el ámbito oceánico que se extiende entre Sudamérica y la península Antártica. Los resultados dados a conocer en fecha reciente permiten concluir de manera general que el relieve submarino más que asumir la alguna vez supuesta forma de una llanura abisal, está formado por pliegues y elevaciones, caso este en que las mismas alcanzan alturas que las acercan a las superficies oceánicas, sugiriendo un proceso dinámico que tanto puede admitir eventuales afloramientos como hundimientos de las formas -montes- con relación a dicho nivel.

Estas investigaciones han permitido registrar numerosos accidentes de la especie de que se trata, de los que quizá el más sorprendente -y sugerentees el denominado monte Sars, (Sars Seamount), situado a $59^{\circ} 43^{\prime}$ de latitud sur y $68^{\circ} 50^{\prime}$ de longitud oeste, ubicación que calificamos de excepcional e importante por hallarse en la mitad de la distancia que media entre la tierra americana austral más extrema y la más septentrional del continente antártico, en el límite de la línea de convergencia antártica y, además y no menos significativo, dentro y en la inmediata proximidad del limite de la Zona Económica Exclusiva (ZEE) de Chile que en esta parte se extiende sobre el mar de Drake.

Dista por fin 200 millas náuticas al sur del islote Águila del archipiélago Diego Ramírez, situándose prácticamente sobre la misma posición respecto del meridiano. Estas circunstancias de ubicación califican la importancia de la posición desde diferentes puntos de vista, en especial desde el científico.

El monte Sars se eleva unos 4.000 metros desde su base y su cima se sitúa a unos cien metros bajo el nivel del mar. La misma parece tener una superficie plana que sirve de domicilio a una rica fauna

generalmente identificado como volcán submarino extinto o bien, una guiota. Forma de relieve submarino aislado. Y también a una elevación de fondo marino de 1000 o más metros de altura de forma cónica, puede ser de cima plana (llamado guiota) o en punta (llamado pico marino). Los montes submarinos pueden ser discontinuos, o alineados según dirección o agrupados al azar. También pueden estar conectados en su base y alineados a lo largo de una dorsal. 


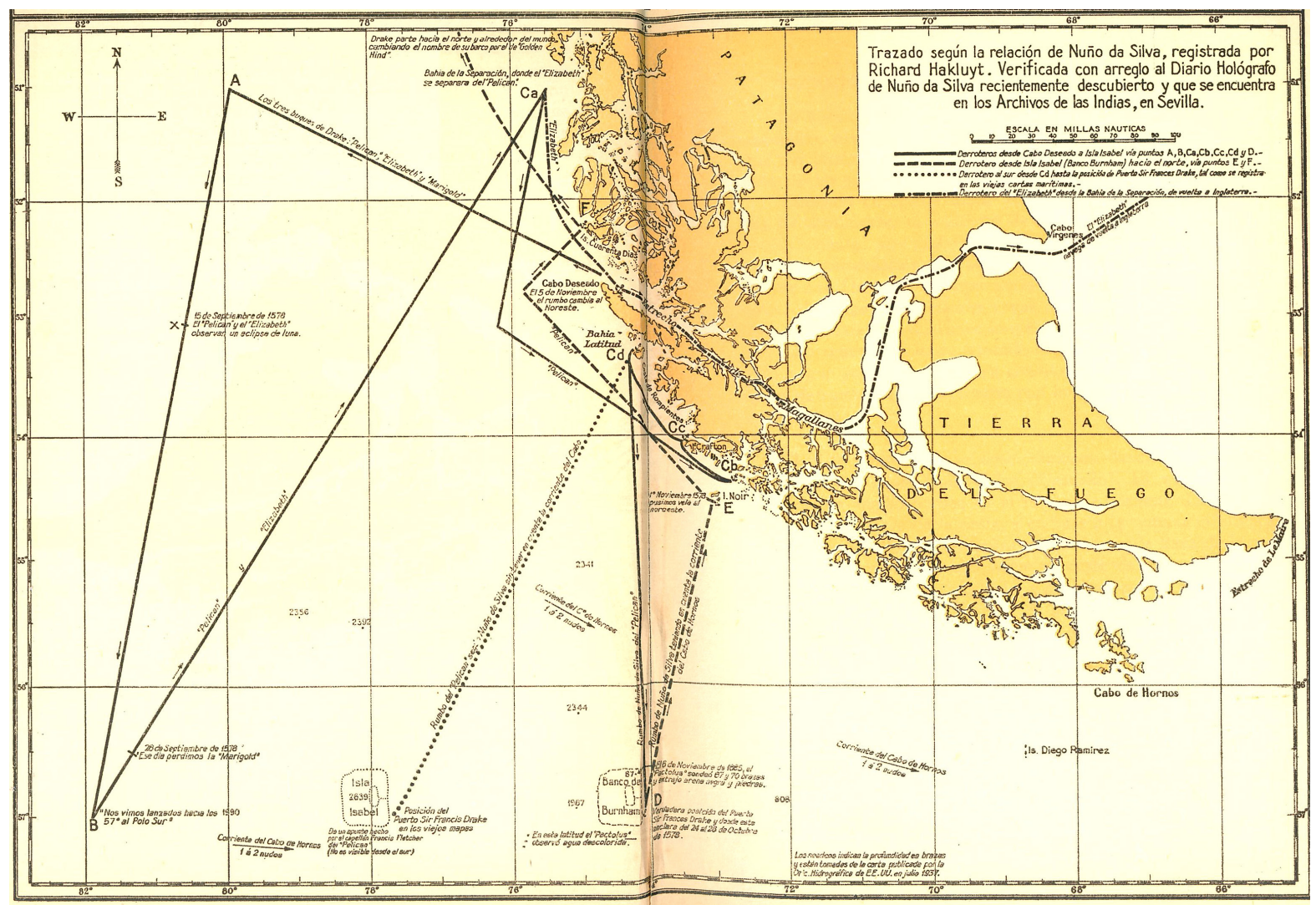

Fig. 1. Mapa del sector sudoridental del Pacífico, Patagonia Austral y Tierra del Fuego, donde se indican las derivaciones de Drake y las posiciones dadas para la isla Elizabeth y el banco Burnham (reproducido de Riesenberg, 1946).

bentónica que incluye grandes esponjas y formas fósiles de corales cuya antigüedad se ha estimado en 12500 años AP (Bohoyo et al. 2016).

El descubrimiento, ciertamente notable, ha venido a agregar nueva y mayor importancia al espacio geográfico que media entre Sudamérica y la Antártica al ofrecer más que una posibilidad, la probabilidad de haberse dado en remotas épocas geológicas una vinculación entre ambos sectores continentales a modo de un "puente insular" alternativo al hasta ahora considerado (Arco de las Antillas Australes) $y$, como tal, fuente de estudios específicos de gran interés sobre aspectos geológicos y biológicos.

Esta circunstancia, añadida a las consideraciones hechas por investigadores chilenos y extranjeros pertenecientes a las Universidades de Magallanes y de Texas A\&M y por el Instituto de Ecología y Biodiversidad de Chile, la Fundación Omora y The National Geographic Society en Estados Unidos de América, han conducido a la revalorización del archipiélago Diego Ramírez y a su vasto ámbito oceánico, incluyendo los montes submarinos hasta ahora registrados, habida cuenta específicamente de su ubicación geográfica en el hemisferio austral de la Tierra, única y excepcional para el desarrollo de los más variados estudios de interés para la ciencia universal y para la humanidad toda. Este proceso de valorización concluyó con la propuesta formal hecha al Gobierno de Chile para la creación del Parque Marítimo islas Diego Ramírez - paso Drake con una superficie de 144.000 kilómetros cuadrados que se extiende sobre el mar de Drake desde el último archipiélago hasta el límite de la Zona Económica Exclusiva, con el objeto de su preservación y su estudio científico atendida su enorme significación bajo distintos aspectos. La propuesta, debidamente informada y sostenida ante los organismos y autoridades competentes, fue acogida y formalizada por decreto firmado por la Presidenta Michelle Bachelet el 27 de febrero de 2018, según el cual se crea un conjunto de nuevos parques nacionales y áreas marítimas protegidas en el territorio chileno. 


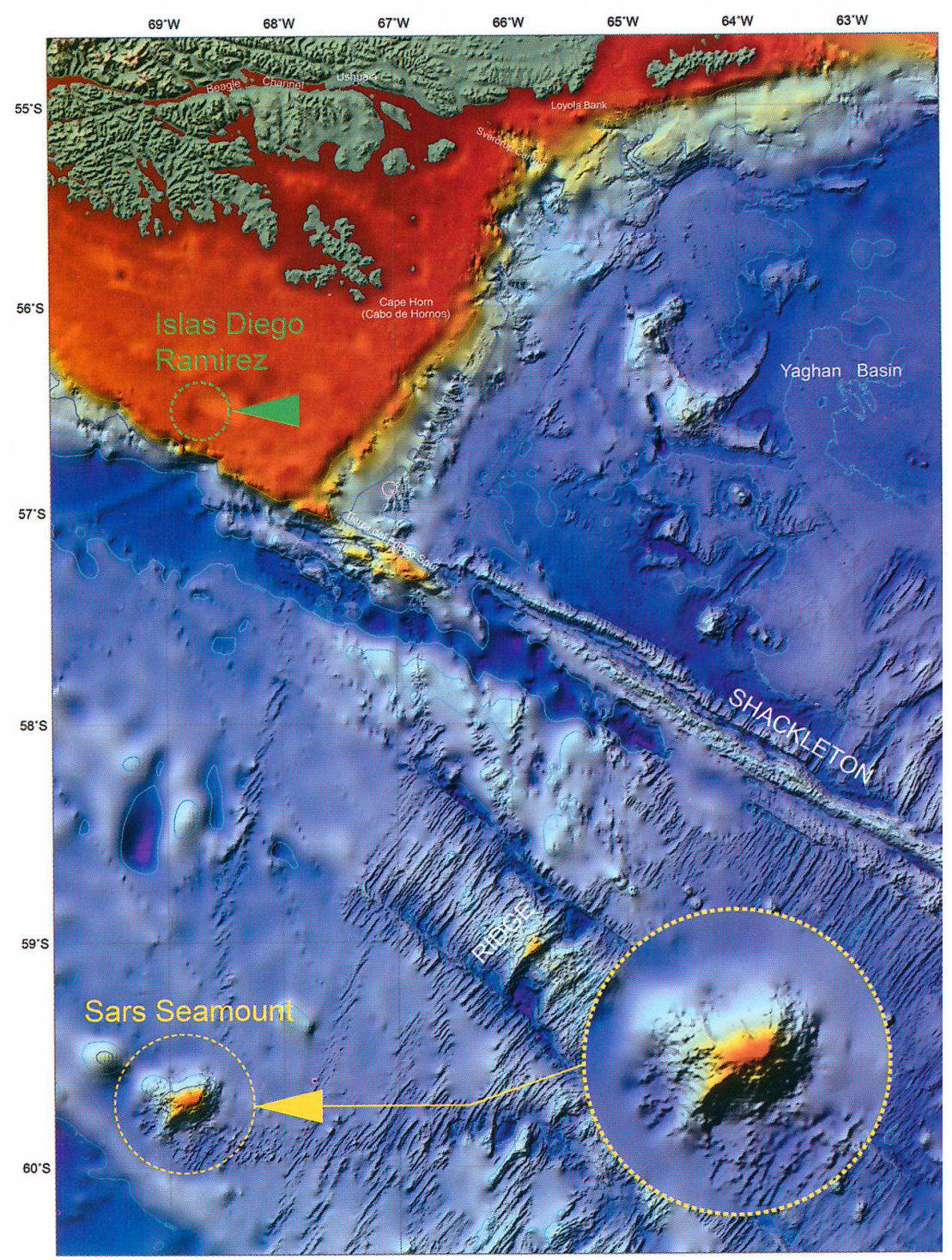

Fig. 2. Fondo submatino del sector paso Drake al sur de Tierra del Fuego, donde se indica la ubicación del monte Pond.

\section{ALGUNAS CONJETURAS A MODO DE CONCLUSIÓN}

Ninguno de cuantos se han ocupado del viaje de Francis Drake, especialmente en lo tocante al alcance geográfico de su histórica derivación al salir al Pacífico desde el estrecho de Magallanes en 1578 , y a su presunto avistamiento de una isla océano adentro, ha puesto en duda la veracidad de este hecho y, como se ha visto, únicamente se ha discutido sobre las coordenadas de situación dadas para la tierra avistada y visitada. Así para unos estuvo próxima al continente americano ubicándose en la zona periférica occidental del archipiélago fueguino; y para otros estuvo situada mar adentro, lejos de la costa continental y para explicar su desaparición posterior se ha postulado (Riesenberg) la hipótesis de su hundimiento por causa de un cataclismo.

En la consideración de esta hipótesis cabe preguntarse acerca de cuánto se conoce acerca de la historia telúrica, en el caso de la evolución que 
ha dado forma a la corteza terrestre y de manera particular a la que actualmente se encuentra bajo el nivel del mar. Hasta donde sabemos parece ser más lo que se ignora que lo que se conoce sobre esta materia por la dificultad obvia que representa la difícil accesibilidad al suelo submarino. Ahora bien, si la conformación del mismo, de acuerdo por lo revelado por las más recientes investigaciones, es más irregular que lo supuesto con anterioridad de las mismas, debiera aceptarse la posibilidad de hallazgos de más formas montañosas cuyas cimas, en la dinámica terrestre, alguna vez estuvieron tan próximas al nivel del mar o aun por encima del mismo que permitieron a ocasionales navegantes algunas observaciones de tierras emergidas antes desconocidas. En la historia de los viajes y exploraciones oceánicos abundan tales referencias, como ha sido el caso de islas avistadas en el mar de Chile durante el siglo XIX y nunca vueltas a ver por segunda vez.

¿Pudo ocurrir lo mismo en el ámbito oceánico austral al sur y sudoccidente de la Tierra del Fuego? ¿Pudo haber sido la misteriosa isla Elizabeth uno de los territorios océanicos objeto de tal fenómeno? Y en una conjetura más atrevida, ¿pudo el actual monte Sars haber sido una isla emergida en algún momento de la historia geológica de la Tierra? Y si así pudo ser ¿qué clase de vida natural pudo darse en su superficie y en su entorno litoral y oceánico y cuál su relación posible con otras formas y asociaciones bióticas conocidas? Estas y muchas otras preguntas pueden hacerse a la vista del extenso ámbito oceánico que se ubica al sur y suroeste del cabo de Hornos e islas Diego Ramírez en lo tocante a su gran potencial como objetivo de estudios científicos tanto en sus geoformas como en el mar que las cubre.

Alejándonos del mito y acercándose a la realidad es posible que avistadas o no en algún tiempo de la larga historia geológica del planeta hubiera tierras emergidas en el ámbito oceánico austral de América después cubiertas por el mar y de la que los montes submarinos que han sido relevados y revelados recientemente constituyan su manifestación fisiográfica. Estas expresiones son, a nuestro juicio, objetivos de interés científico en diferentes aspectos y merecen la atención particular de organismos académicos y técnicos en procura de su debido conocimiento. Queda abierta así a la imaginación la gama de sugerencias acerca de las vinculaciones que se dieron en el pasado entre Sudamérica y la Antártica.

\section{BIBLIOGRAFÍA}

Bohoyo F., Larter, R. D., Galindo-Zaldivar, J., Leat, P. T., Maldonado, A., Tate, A. J., Flexas, M. M.,... \& Riley, T. R. (2016). Bathymetry and Geological Setting of the Drake Passage (1:1.500.000) BAS GEOMAP 2 Series, Sheet 7, British Antarctic Survey. Cambridge U.K.

Díaz-Naveas, J., \& Frutos, J. (Eds.). (2010). Geología Marina de Chile. Servicio Hidrográfico y Oceanográfico de la Armada de Chile/Comité Oceanográfico Nacional/ Pontificia Universidad Católica de Valparaíso/Servicio Nacional de Geología y Minería. Valparaíso.

Martinic, M. (1998). Drake y el descubrimiento de la insularidad fueguina. La evidencia cartográfica. Anales del Instituto de la Patagonia, Serie Ciencias Sociales, 26, 5-22.

Riesenberg, F. (1946). Cabo de Hornos. Buenos Aires: Librería Hachette S.A.

Seixas y Lovera, F. (1690). El curioso Mapa de la Región Magallánica de Francisco de. Boletín de la Academia Chilena de la Historia, 107, 385-400.

S/Autor (2017). Parque Marino Cabo de Hornos-Diego Ramírez. Informe Técnico para la Propuesta de Creación. Programa de Conservación Biocultural Subantártica-Universidad de Magallanes. Punta Arenas: Ediciones de la Universidad de Magallanes. 